\title{
The fiddle of using the Paralympic Games as a vehicle for expanding [dis]ability sport participation
}

\author{
P. David Howe and Carla Filomena Silva
}

\begin{abstract}
In this paper we highlight the need to explore the excessive significance given to the Paralympic Games as a vehicle for the encouragement of participation of people with a disability within sport. The media spectacle around the games that the International Paralympic Committee (IPC) has worked tirelessly to develop has become, for policy makers and the public alike, a sufficient outlet for disability sport provision. We argue that the honourable goals of the IPC articulated through the ethos of Paralympism have been assumed to be valid for all people with a disability, yet in terms of widening participation, their utility is limited, as the Paralympics themselves are exclusionary. This paper first illuminates the relationship between the International Olympic Committee (IOC) and the IPC before we turn our attention to the ethos of Paralympism. Highlighting the necessity for 'sport for all' we show how a human rights lens, aided by a capabilities approach can facilitate better ways to educate the public about the need for equality of access to sporting participation opportunities.
\end{abstract}

\section{Introduction}

Today the Paralympic Games are presented as part of the Olympic Festival, and are formally part of the Olympic Movement. Internationally the International Paralympic Committee (IPC) and the International Olympic Committee (IOC) signed an agreement in 2001, which benefited the IPC by providing it with long-term financial support, access to high quality facilities in which to hold the Paralympics, and countless other commercial opportunities. For the IOC the positive publicity garnered praise for the charitable support of the IPC at a time when the organization's core values were being publicly scrutinized in light of scandals associated with the 2002 Salt Lake City Winter Olympic Games. In 2003 this agreement was amended to transfer "broadcasting and marketing responsibilities of the 2008, 2010, and 2012 Paralympic Games to the Organizing Committee of these Olympic and Paralympic Games" (IPC, 2003, p. 1). Subsequently this agreement has been amended to run up until after the 2020 Tokyo games (IPC 2012). While agreements such as this eases financial concerns for the IPC, it may also force a restructuring of disability sport. The IOC demands that the Paralympic Games are restricted in size to 4,300 athletes. Limiting the size of future Paralympic Games in the eyes of the IOC makes it a more manageable product to market. The marketing of the Olympics and Paralympics as a single entity has however undermined the IPC's autonomy to use the Paralympic Games to educate the public about [dis]abled athletes ${ }^{i}$ and disability issues more broadly (Howe, 2011; Purdue and Howe, 2012a). The erosion of this educational imperative is problematic because it collides with one of the IPC's explicit aims: the effective promotion of opportunities for people with disabilities to get involved in sport. Moreover, the IPC's dictum "empower, inspire and achieve" (Purdue and Howe, 2012b) suggests the Paralympic movement aims to emancipate its athletes in hope that their performances will inspire others to great achievements.

For over a quarter of a century the IPC, and its network of national affiliates, has placed integration of the [dis]abled in sport firmly on the sporting agenda (Labanowich, 1988; Steadward, 1996; Vanlandewijck and Chappel, 1996) and celebrated closer harmony with the IOC (Howe, 2008). To date, this process has been widely accepted as a positive step. However, there has been little critical reflection upon its impact. It is our belief that there is also an assumption, by policy makers and 
the public alike, that Paralympic sport is synonymous with the spectrum of disability sport opportunities and this is hindering the expansion of participation and the ideal of equality in sport for [dis]abled people.

This paper offers a culturally driven interpretation of human rights and stresses their value in understanding issues related to social justice and the value of sports participation for [dis]abled athletes. Beginning with an outline of Olympic and Paralympic ethos, this paper then turns its attention to the concepts of integration. We then highlight how a human rights lens, aided by a capabilities focus, can be used to illuminate a better understanding of 'sport for all' and the utility of this movement as an educational tool for policy makers and the public alike. This education, we believe is conditional upon an expansion of opportunities for people with disabilities to engage in any form of sport or physical activity.

\section{Paralympic Ethos}

Paralympism is an ideology celebrated by the IPC that has been developed in an attempt to establish a universal ethos that extends beyond the Paralympic Games in much the same manner that Olympism has transcended the more established Olympic Games (Howe, 2008). Some scholars working within the field of disability sport have argued that a philosophy of Paralympism is not needed because the discrimination of individuals regardless of ability is against the principle tenets of Olympism and therefore this philosophy is appropriate for the Paralympic movement (Landry 1995; Wolf et al. 2008). Clearly there are examples of harmony between Paralympism and Olympism. The motto of the Barcelona '92 IX Paralympic Games "Sport without limits" resonates with Olympism. Also the IOC's definition of Olympism is believed by some to reflect the centrality of the Paralympic Movement. The fundamental principles of the Olympic movement enshrined in the Olympic Charters (IOC, 2004, 9) suggest that

Olympism is a philosophy of life, exalting and combining in a balanced whole the qualities of body, will and mind. Blending sport with culture and education, Olympism seeks to create a way of life based on the joy of effort, the educational value of good example and respect for universal fundamental ethical principles.

It further suggests

The goal of Olympism is to place sport at the service of the harmonious development of man, with a view to promoting a peaceful society concerned with the preservation of human dignity.

Taking this at face value, "the expression "Paralympism" appears to be somewhat superfluous, pleonastic; "Olympism" is sufficient ... it says it all.' (Landry 1995, 5). In fact during the 1956 Olympic Games 'the International Olympic Committee awarded the Fearnley Cup to the organisers of the International Stoke Mandeville Games [the antecedent of the Paralympics] for "outstanding achievement in the service of Olympic ideals"'(Goodman 1986:157). According to Parry 'Olympism is a social philosophy which emphasises the role of sport in world development, international understanding, peaceful co-existence, and social and moral education.' (2004:1). As a result, compliance with it can add virtue to the Paralympic movement. 
However, since the Paralympic movement possesses a distinctive cultural history and matching habitus (Howe, 2008) it needs to establish a distinctive philosophy. There are also those who advocate simply the use of Olympism (Wolff et al. 2008) as a sign of the growing harmony between the Olympic and Paralympic Movement. In practice, however, both the Olympic and Paralympic games exclude the [dis]abled or to put it another way 'those who can't'. Yes, Olympism may be an inclusive ideology (Wolff et al. 2008) but the practice of high performance sport is not (Jones and Howe 2005). In this sense, when thinking of the equality of opportunities within sport implicit in a "sport for all" approach both ideologies would fall short.

Almost three decades ago Labanowich (1988) argued for the aglutination of the Paralympic Games into the Olympics based upon the number of countries and athletes contesting various sports within the Paralympic Games. While there may be some validity in this move we would argue that the essence of Paralympism is worth keeping separate (Howe, 2008). In The Fundamentals of the Philosophy of the Modern Olympics, Courbertin, the 'father' of the Olympic Movement, highlights the degree to which an extremely exclusionary physical culture may be used as a vehicle to achieve sporting excellence when he states "For a hundred men to take part in physical education, you must have fifty who go in for sport. For fifty to go in for sport, you must have twenty to specialise, you must have five who are capable of remarkable physical feats." (1956 [1935]:53). A place in the Olympic Games is only available to the best among the best. This is not a commonplace situation in Paralympic sport. From data collected in the context of Paralympic sport it is clear that it is easier across the board to be selected than it is for the Olympic Games (Purdue and Howe, 2012a, 2012b). This is the case because many of the classes of disabled athletes struggle to recruit enough athletes to hold an event as there must be ten athletes on an event world ranking lists for individual sports to be contested at the Paralympic Games (Howe, 2008). Even in the cases where there is exceedingly tough competition, notably class T54, the most 'able' of track wheelchair racers, access to technology may be a more determining factor than athletic ability. Of course access to financial support is a factor in both able and disable sport but there are not events cancelled at the Olympics due to a lack of competitors.

Although the Paralympic movement as a whole does not create a sporting aristocracy in the same extent as Coubertin believed the Olympics did, it has created its own identity. The establishment of the dictum 'empower, inspire and achieve' at the heart of Paralympism is distinct from the Olympic motto. In a sense the Paralympic Games cannot follow Coubertin's vision of the cycle of Olympiad to provide the youth of any moment in time with the opportunity to compete in an international context. By stating that "The Springtime of human life is found in the young adult who may be compared to a superb machine up and ready to enter, into full activity." (Coubertin 1956 [1935]:53-54), Coubertin believed that the Olympics were an ideal environment for fostering the youth. Yet, many athletes who compete in the Paralympic Games are 'eligible' as a result of a traumatic occurrence in life which has no fixed time in the development of the individual. Rehabilitation following traumatic injury in a sense can be about creating another individual or a re-birth (Seymour 1998) and opportunities to be engaged in sport, including at the high performance end of the spectrum can play an important part in this process. In other words Paralympians are generally older than Olympians and rehabilitation continues to be a feature of contemporary disability sport for the disabled. 
While the IPC has distanced itself from any explicit discussion of Paralympism, relying instead on the dictum Empower, Inspire, Achieve, the vision of the movement is 'To enable para-athletes to achieve sporting excellence and inspire and excite the world' ${ }^{\text {ii }}$ This vision is designed to create opportunities for athlete empowerment from the point that they enter the sport up to and including the Paralympic Games. It is a lofty goal but all too often the IPC is less concerned with the full participation of [dis]abled people within sport and society more generally And more concerned with replicating the spectacular success of the Olymic movement (see Howe, 2008). As such the Paralympic movement like that of the Olympics 'all benefited from the benign myths of origin rooted in reverential attitudes toward the personal qualities of their respective founding fathers and the salvational doctrine they created.' (Hoberman 1995:3). While de Coubertin is celebrated as the father of the Olympic movement, Ludwig Guttman a neuro surgeon of German heritage is seen as founding father of the Paralympic movement (Goodman, 1986).

Much of the myth surrounding the Olympic movement is that the chivalric tendencies of the movement, the knightly ethos of officials and athletes alike "was the precise negation of socialist rationality, solidarity, and the improvement of ordinary life for the greatest number.' (Hoberman 1995:19). The first Paralympians fit this model albeit as wounded ex-servicemen (Guttman, 1976; Goodman, 1986; Howe, 2011). Yet unlike 'Coubertin's original version of the idealized male action figure was the "débrouillard," the dynamic "go-getter" type (Hoberman 1995:22) Paralympians have until recently be seen as charity cases (Howe, 2008). As such it is not surprising that the Paralympic Games is seen as detrimental by the broader Disabled Persons movement (Purdue and Howe, 2012b). Guttmann best summed this up in 1976 when he scored an own goal in his classic pronouncement 'Mens sana in corpore sano (Healthy mind and healthy body) should read Mens sana in corpore sano et invalido! (Healthy mind and healthy body or an infirm [weak or feeble] body) (Guttmann 1976: 13). This statement highlights that the Paralympic Movement is in part about providing sporting opportunities for less than able bodies. There is of course a spectrum and hierarchy of ability within disability sport. Not everyone with a disability has the physical gifts to be a Paralympian. But there may also be those who have the physical gifts but whose impairment group is excluded from the movement for historical reasons (Howe, 2008). According to Purdue and Howe (2012, p. 203):

The impaired body, in all its different configurations, should not be treated as the social pariah of the elite sporting world which accommodates a range of able bodies, be they tall, short, male, female, white, non-white, lean or so muscular to the extent they can be classified as clinically obese. The importance lies in seeing all bodies in the context of the sport in which they compete. All bodies possess limitations, even so called able bodies. It is important to appreciate elite disability sport on its own merits, just as sports fans do across the diverse spectrum of sporting practice that we have socially constructed overtime and engage with today.

In spite of these views we still believe Paralympism personified in the dictum Empower, Inspire, Achieve is a goal worth pursuing. However, there seems to be a 
tendency to present the expansion of the Paralympic Games as the proof that the process of integration of [dis]abled people in sport is being achieved. It has to be emphasised however, that the Paralympic Games are, in many ways, an exclusionary phenomenon and therefore ineffective as the only banner for the widespread expansion of opportunities for [dis]abled people to be involved in sport. There is therefore a need to create and promote more diverse sporting opportunities for the [dis]abled than the Paralympics, if participation in sport is going to be expanded (Nixon, 2007). We turn our focus now on the expansion of opportunities more widely. In doing so, we turn our attention to integration in sport since as we have illustrated above the Paralympic movement is unsuitable to achieve this aim to its fullest extent.

\section{Integration in sport}

The integration of people with impairments within society has been seen over the past few decades as a marker of enlightened thinking and a sign of progress towards equality of opportunities to participate in society. The interdisciplinary field of disability studies has however been critical of the concept of integration since it implies to some that people with disabilities are required to change in order to join the mainstream (Northway, 1997). Oliver (1996) has gone so far as to suggest that integration is based on concepts of normality. In other words the concept of integration requires members of the disabled community to adopt an 'able' disposition in order to become members of the mainstream sporting community. Because of these shortcomings Oliver dismisses integration as being heavily laden with policy rhetoric and sees the term inclusion, because of its association with politics as more appropriate (Oliver, 1996; Northway, 1997). Inclusion, to some, means that members of the disability community have a choice in whether to fully embrace the mainstream community.

[E]quality (defined as 'the participation and inclusion of all groups') may sometimes be best achieved by differential treatment. This does mean that if oppressed groups so choose they can opt for groups-specific recognition in policy and provision, since within an inclusive approach difference would be accepted or included as a natural part of the whole (Northway, 1997, p.166)

Following these debates there has been a shift within the literature on disability from the dichotomy of integration/segregation to another where inclusion/exclusion are seen as a more politically appropriate way to advocate the acceptance of the [dis]abled. We advocate seeing integration as a literal intermixing that entails the culture of both groups adapting to a new cultural environment.

Community integration is the acquiring of age, gender, and cultureappropriate roles, statuses and activities, including in(ter)dependence in decision making, and productive behaviours performed as part of multivariate relationships with family, friends, and others in natural community settings (Dijkers, 1999, p. 41)

In other words integration is 'a multifaceted and difficult process, which although it could be defined at a policy level rhetoric, [is] much less easy to define in reality.' 
(Cole 2005:341). The difficulty when evaluating the success of integration policies is that the balance between the philosophical position and the reality (in this case a cultural sport environment) is not always clear or evident. Simply exploring the policy landscape means that any interpretation is devoid of any explicit cultural influences, even though all policy is in fact, a cultural artefact itself. This being said the aim of integration, as we understand it, is to allow the [dis]abled to take a full and active role within society. The ideal would be

[a] world in which all human beings, regardless of impairment, age, gender, social class or minority ethnic status, can co-exist as equal members of the community, secure in the knowledge that their needs will be met and that their views will be recognised, respected and valued. It will be a very different world from the one in which we now live (Oliver and Barnes 1998, p. 102)

In the context of sport, the Paralympic movement is often seen as a marker of a successful process of integration of people with disabilities. Yet, this utopian vision is hard to achieve. By its very nature, elite sport is selective as Bowen suggests "Within professional sport, though, all but the super-able 'suffer' from 'exclusion or segregation.'" (2002, p. 71). In other words the pursuit of excellence that is central to high performance sport, including the Paralympic Games is not an integrated environment. Therefore it is problematic when the public and policy makers use the Paralympic movement as a substitute for the disability sport. The act of including certain bodies in the Paralympic Games and excluding others (Jones and Howe, 2005; Howe, 2008) is in itself not a problem, as they are afterall, the pinnacle of disability sport competition. However, this becomes paradoxical when Paralympics are used as synonomous with the whole spectrum of disability sport opportunities.

A successful level of integration is incompatible with the selective nature of elite sport. In order to fully understand the success or failure of integration within sport it is important to begin to get a sense of the culture of disability sport. Work exploring disability sports culture and the place of the Paralympic Games within this it is essential to articulate an agenda to increase participation (Howe, 2008). More recent research highlighting the use of Paralympians as role models to enhance integration is problematic (Purdue and Howe, 2012b; Howe and Parker, 2012) in part because of the limited spectrum of acceptable embodiment within the Paralympic movement.

Given the limitations of using the Paralympic Games in promoting deeper levels of integration of people with disabilities in sporting structures, we turn to the concept of human rights to provide some clarity and enhance our quest for equality.

\section{Human Rights and [Dis]ability Sport}

Conceptualisation of human rights as the by-product of legislative social justice (Rawls 1971) will be explored in order to establish a framework to determine whether integration within the practice of sport can be seen to have been successful. Human rights are principles regularly used to highlight the wrong being done to an individual on the basis of an infringement of a basic need that is considered inherently 'natural'. The concept of 'natural rights' that should govern humanity comes originally from the 
work of philosopher John Locke in the seventeenth century (Locke [1689] 1970) and while human rights are not seen to be 'natural' today there is a sense in the discourse on rights that there is something in all human societies leading us to believe in inherent basic rights (Donnelly 1985; Freeman 2002). However, philosophers remind us that a 'right' can only be achieved as the end result of a moral argument and not as a premise for the discussion in the first place. Following Harris

when it is said that someone has a right to something, that just means that in all circumstances of the case she should not be hindered in or prevented from doing or achieving something. And if it is asked why she should not be hindered, the answer is not 'because she possesses something called a right which has been independently established or "discovered",' but simply because there are good moral reasons why it is wrong to hinder her (1985: $\mathrm{xi})$

In other words, for the purpose of this paper rights should not be seen as an object or a thing an individual possesses but as an entitlement that is the result of a moral or legal argument. As a result the Universal Declarations of Human Rights of the United Nations (UN) was designed to highlight that all people should be treated with respect. This statute should not be seen as an answer to human rights violations but rather as a marker that they do occur. Afterall the UN is not a utopian body but a political one and since its Declaration was written there have been hundreds of examples of the gaps between the ideology associated with the establishment of universal human rights and the lived reality. As Freeman suggests 'It is politically important that human rights have been codified in international and national law, but it is a mistake to believe that the legalization of human rights takes the concept of politics out.' (2002:10).

UN human rights legislation is not intended to impose a legal obligation upon nation states but offer a set of guidelines that are seen as universally good behaviour. In other words the Universal Declaration of Human Rights outlined what the UN felt were 'moral and political principles that could make a prima facie plausible claim to universality' (Freeman 2002:36). The claims for universality are laid out in Article 2 which states that we are all entitled to freedoms 'without distinction of any kind, such as race, colour, sex, language, religion, political or other opinion, national or social origin, property, birth or status.' To reinforce this statement Article 7 states that all entitled to equal protection of the law without discrimination. While implementation of human rights was designed to eliminate human wrongs such as political oppression and racism it is important that their implementation follows on from the development of a just society (Donnelly 1985). Societies continue to place a great deal of importance on human rights. The development of both the Vienna Declaration of 1993 on minority rights and the more recent Convention on the Rights of Persons with Disabilities of 2006 attest to the fact that human rights are not understood universally. In effect rights exist in a hierarchy from local customs national and international laws - it is normal for individuals or groups to seek resolution at the more local level to try to resolve problems. Yet it is the state (or rather those who signed up to these statutes) that has the obligation towards human rights which leave the way open for unseen violations in the corporate world for example or within the more private sphere of the family. Thus, it seems that despite 
being essential as an ethical barometer, the concept of human rights lack in practical currency.

In order to address these concerns we turn to Martha Nussbaum who has developed a version of Amartya Sen's capabilities approach, proposing a list of 10 capabilities that are as universal as possible while being culturally sensitive to the quality of life of individuals (Nussbaum 2006; Malhotra 2008). Defending legal enforcement in terms of guaranteeing a minimum level of enjoyment of each one of these 10 capabilities, the list acts as a litmus test for the quality of life of individuals motivating moral action. As Nussbaum suggests

'[t] he capabilities approach is a political doctrine about basic entitlements, not a comprehensive moral doctrine. It does not even claim to be a complete political doctrine, since it simply specifies some necessary conditions for a decently just society, in the form of fundamental entitlements of all citizens' (2006:155).

Nussbaum (2006) uses the case of the disabled population in part because this segment of global society is absent from more conventional understandings of justice as triumphed by Rawls in his influential The Theory of Justice (1971). According to Nussbaum Rawlsian 'justice as fairness' is not appropriate for the achievement of social justice for marginalised groups, whereas a capabilities approach evaluates the individual in question in relation to fundamental capabilities such as living a full life, bodily health, freedom of movement and affiliation. Also included are abstract capabilities related to the senses of imagination and the capability for reason. (Nussbaum 2006:76-8). "Capability can be regarded as a combination of an individual's personal characteristics (such as age or physiological impairment), [a] basket of purchaseable goods [as a measure of their standard of living] and the individual's environment in the broadest sense' (Malhotra 2008: 85). In other words, a person's quality of life should be determined by the relationship between the physical and social environment and what their standard of living equates to in an individual context. As such since the unit of moral analysis is the individual, the capabilities approach may help overcoming the lack of practical relevance of a human rights approach to equality.

The response by the UN to the polemic of various human rights groups against the claims of universalism and the problems associated with cultural imperialism was the establishment of the Vienna Declaration of 1993 that included a number of special categories, such as women, children, minorities, indigenous people, disabled persons, refugees, migrant workers, the extremely poor and the socially excluded. There is a need to recognise these holders of human-rights because these groups are more prone to human rights violations than the majority and they can get lost in the 'universality' of human rights that can so easily if not checked can drift toward ideologically inappropriate cultural imperialism (Freeman 2002). To further solidify the case in 2006 the Convention on the Rights of Persons with Disabilities placed the spotlight on the disabled community and included Article 30 which includes suggestions of the right to participate in cultural life including sport. The problem with disability specific conventions is that it singles out 'the disabled' as a group that are in need of being helped. Many people with disabilities, including a high proportion of Paralympians do not require or accept their status as universally vulnerable people. 
The documents revered and celebrated in some disability rights circles inherently lack the clout that disability activists often wish they had. For example one of the capabilities Nussbaum highlights is the right to play and it is fair to assume we would all agree with that requirement for a good life. Yet the simple act of playing is clearly distinct from codified professional sport such as the Paralympics. Even nations that enacted all UN human rights agreements have limited resources to police their implementation. Recent work by Friedman and Norman (2009) on legal issues surrounding the rights of Paralympians in receiving equal treatment, in terms of financial and medical support compared to Olympians within the United States highlights that in terms of equality there is still a long way to go. What makes this position so unpalatable is that the tenets upon which the UN understands human rights are based are clearly inequitable.

MacIntrye (1999) reminds us, however, that all human beings are vulnerable and in fact we are dependent rational animals and this being the case we should as a species be more adaptable to a common good.

$[\mathrm{H}]$ ow much is involved in allegiance to a conception of the common good that requires both the virtues of the independent practical reasoner and the virtues of acknowledged dependence. For this is a good common to the very young and to the very old, as well as to mature adults, to the paraplegic and to the mentally backward as well as to the athlete and to those engaged in intellectual enquiry, a good that has regard to every vulnerability to which our animal identity and our animal nature, as well as our specifically human condition expose us.' (MacItyre 1999:165-6, Italics added).

It is in the pursuit of a common good that the Universal Convention for Human Rights and its various latter day 'offspring' were developed but clearly there are major problems with their implementation in practice. While the concept of human rights developed by the UN were created to limit the power of governments, the problem is that democracy by its very nature limits the rights of minorities (Freeman 2002). In a sense human rights in individual nations need to be balanced with other values of social order.

Stammer (1999) suggests that we examine power relations and focus upon the role of institutions and social movements in the distribution of it rather than simply exploring the legal formalization of rights. In this respect the IPC and the broader Paralympic Movement have a role to play through the development of a universalising ethos. Unfortunately, of late, the Paralympic Movement has become commercialised which traditionally has been counterproductive with respect to human rights in much the same way as democracy was subverted by the will of those individuals with economic power. The problem is that ' $[\mathrm{t}]$ he Universal Declaration is based on the assumption that individual human rights, including the prohibition of discrimination and the right to practice one's culture, are sufficient to protect cultural minorities.' (Freeman 2002:114). This is problematic in so far as the political theory of liberal democracy has not been designed historically to solve the problems of cultural minorities such as the disabled in part because the classical construction of democracy presupposed culturally unified people. In the sports world where we champion participation for all 
we know there is great diversity and therefore individual differences need to be acknowledged and celebrated. This would lead us to the development of a much broader spectrum of sporting opportunities than currently exists today.

\section{'Sport For All'}

Despite its limitations, the concept of human rights appears to have salience when looking at the inequitable treatment of people within the realm of sport. United Nations Educational Scientific and Cultural Organisation (UNESCO) established the International Charter of Physical Education and Sport in 1978 which stated in Article 1 that the practice of physical education and sport is a right for all. This charter has ignited the emergence and development of the 'sport for all' movement. The relationship between human rights and sport is further reinforced by a key element within the Olympic Charter which means they are even believed to be of concern at the high performance end of the sporting spectrum. Due to its political currency of sport, and despite its limitation, the concept of human rights seems adequate to initiate the discussion the unequal opportunities for people with disabilities to participate in sport as a case of social injustice.

Work by Kidd and Donnelly (2000) and Donnelly (2008) highlights the value of researching human rights issues as they relate to sport and see the actions of the UN as a good starting point from which to achieve 'Sport For All'. However, we must be mindful that the promotion of sport over traditional body cultures does not lead to decline of important traditions that may be just a good for people's quality of life as the practice of sport. Therefore the elevation of sport over other forms of physical education (used in the broadest sense) may not be considered a good thing.

\section{Discussion}

Traditionally scholars and political organisations such as the UN have turned to human rights to gain equitable treatment of marginalised populations. It is our contention however that a reliance upon state governments and international organisations such as the UN is a mistake because all too often the enforcement of legislation is problematic it that it relies upon marginalised individual to take large bureaucratic organisation to task if rights have been violated. The act of drafting both the Vienna Declaration of 1993 and the more recent Convention on the Rights of Persons with Disabilities of 2006 and enacting them within national government is unlikely to facilitate a more integrated society. That being said these statutes have largely been a success in the West if we consider the capabilities approach triumphed by Nussbaum (2006) and focus on sporting participation which we believe adds to a person's quality of life.

The capabilities paradigm is aligned with ideals of human development that gather significant and cross cultural international consensus. In many respects, this dovetails nicely with human rights philosophy with the added benefit that the 
focus on individual's life assessment acts as a potent weapon against discrimination (Silva and Howe, 2012 p.38)

Access to Paralympic sporting provision is problematic for two reasons in terms of equality. Firstly the nature of high performance sport is such that some people will always be excluded due to a lack of ability (Bowen 2002; Jones and Howe 2005) and secondly the vast number of [dis]abled athletes are excluded from the Paralympic provision. As long as policy makers assume Paralympic sport is [dis]ability sport many of those with a desire to participate will not have the opportunity.

To the outsider the inclusion of Paralympic Games within the matrix of the Olympic Festival may be seen as a statement of a progressive world view in tune with the need for adherence to human rights. However, a critical examination highlights that complete integration within sporting provision is problematic. As a result we can see a heightened the social division between the able and the [dis]abled. Integration or the intermixing of persons previously segregated has changed little in sport settings. Any real change will take a fundamental shift in social attitudes toward physical difference.

Only when we acknowledge the near universality of disability and that all its dimensions (including the biomedical) are part of the social process by which the meanings of disability are negotiated, will it be possible fully to appreciate how general public policy can affect this issue. (Zola 1989:420)

This interpretation should be considered by future policy makers, nationally and internationally when they try to 'better' the world for marginalised populations such as the [dis]abled. We need to educate the public and policy makers alike that Paralympic sport is not synonomus with the spectrum of [dis]ability sport opportunities and until this is achieved expansion of participation and the ideal of equality in sport for [dis]abled people. For far too long there has been an assumption that creating policy and legislation will lead to changes of practice 'sport for all' has been a battle cry for half a century this year - but it is still a dream - let us make it a reality!

\section{References}

Bowen, J. (2002) 'The Americans with Disabilities Act and its Application to Sport', Journal of the Philosophy of Sport, Vol. 29: 66-74.

Cole, B. A. (2005) 'Good Faith and Effort? Perspectives on educational inclusion', Disability \& Society, Vol. 20, 331-344.

Coubertin, P. de (1956 [1935]) 'The Fundamentals of the Philosophy of the Modern Olympics', Bulletin de Comité International Olympique. No. 56. p. 52-54.

Deal, M. (2007) 'Aversive disablism: subtle prejudice toward disabled people'. Disability \& Society Vol. 22 (1): 93-107.

Donnelly, J. (1985) The Concept of Human Rights. London: Croom Helm.

Donnelly, P. (2008) 'Sport and Human Rights', Sport in Society. Vol. 11(4): 381-394. 
Dijkers, M. (1999) 'Community integration: conceptual issues and measurement approaches in rehabilitation research', Journal of Rehabilitation Outcome Measurements. Vol. 3 (1):39-49.Freeman, M. (2002) Human Rights: an interdisciplinary approach. London: Routledge.

Friedman, J.L. and Norman G.C. (2009) 'The Paralympics: Yet another Missed Opportunity for Social Integration', Boston University International Law Review. Vol. 27 (2):345-366.

Goodman, S. (1986) Spirit of Stoke Mandeville: the story of Ludwig Guttmann. London: Collins.

Guttman, L. (1976) Textbook of Sport for the Disabled. HM\&M: Aylesbury, England.

Harris, J. (1985) The Value of Life: an introduction to medical ethics. Routledge: New York

Hoberman, John (1995) 'Toward a Theory of Olympic Internationalism' Journal of Sports History. Vol. 22 (1) p. 1-37

Howe, P. D. (2008) The Cultural Politics of the Paralympic Movement: Through the Anthropological Lens. London: Routledge.

Howe, P. D. (2012) 'Children of a Lesser God: Paralympics and High-Performance Sport' in Sugden, J. and Tomlinson, A. (eds.) Watching the Olympics: politics, power and representation. London: Routledge. pp. 165-181.

Howe, P.D. and Parker, A. (2012) 'Celebrating Imperfection: sport, disability and celebrity culture', Celebrity Studies. Vol. 3 (3) 270-282.

Hughes, A., 1999. The Paralympics. In: R. Cashman and A. Hughes, eds. Staging the Olympics: the event and its impact. Sydney: UNSW Press, 170-180.

IPC (2003)The Paralympian: Newsletter of the International Paralympic Committee. No 3. Bonn, Germany.

IPC (2012) 'IOC and IPC Extend Co-operation Agreement Until 2020' https://www.paralympic.org/news/ioc-and-ipc-extend-co-operationagreement-until-2020: May $5^{\text {th }}$. Accessed 15/04/2016

Jones, C. and Howe, P.D. (2005) 'The Conceptual Boundaries of Sport for the Disabled: Classification and Athletic Performance', Journal of Philosophy of Sport. Vol. 32:133-146.

Kidd, B. and Donnelly, P. (2000) 'Human Rights in Sport', International Review for the Sociology of Sport. Vol. 35 (2) 131-148.

Labanowich, S. (1988) 'A case for the integration of the disabled into the Olympic Games', Adapted Physical Activity Quarterly. Vol. 5. 263-272.

Landry, F (1995) 'Paralympic Games and Social Integration' in De Moragas Spả, M. and Botella, M. (eds.) The Key of Success: the social, sporting, economic and communications impact of Barcelona '92. Bellaterra: Servei de Publicacions de la Universitat Autỏnoma de Barcelona. pp. 1-17

LaVaque-Manty, M. (2005) 'Equal Opportunity and Meaningful Competitions: Disability Rights and Justice in Sports', Disability Studies Quarterly. Vol 25 (3)

Locke, J. ([1689] 1970) Two Treaties of Government. Cambridge: Cambridge University Press.

MacIntyre, A. (1999) Dependent Rational Animals: Why human Beings Need the Virtues. Open Court: Chicago. 
Malhotra, R. (2008) 'Expanding the Frontiers of Justice: Reflections on the Theory of Capabilities, Disability Rights, and the Politics of Global Equality', Socialism and Democracy. Vol. 22 (1):83-100.

Nixon, H. L. (2007) 'Constructing Diverse Sports Opportunities for People With Disabilities' Journal of Sport and Social Issues. Vol. 31(4):417-433.

Northway, R. (1997) 'Integration and Inclusion: illusion or progress in services in services for disabled people', Social Policy and Administration. Vol. 31(2):157-172.

Nussbaum, M. C. (2006) Frontiers of Justice: disability, nationality, species membership. London: Belknap Harvard.

Oliver, M. (1996) Understanding Disability: from theory to practice. Basingstoke, Macmillian.

Oliver, M. and Barnes, C. (1998) Social Policy and Disabled People: from exclusion to inclusion. London: Longman.

Parry, J. (2004) 'Olympism and its Ethic', a paper presented at the 44th International Session of the International Olympic Academy, May/June.

Purdue, D. E. J. And Howe, P. D. (2012a) 'See the sport, not the disability? Exploring the Paralympic Paradox' Qualitative Research in Sport and Exercise. Vol. 4 (2) 189-205.

Purdue, D. E. J. And Howe, P. D. (2012b) 'Empower, Inspire, Achieve: (Dis) Empowerment and the Paralympic Games’ Disability \& Society. Vol. 27 (7): 903-916.

Rawls, J (1971) The Theory of Justice Cambridge, MA:Harvard University Press.

Seymour, W. (1998) Remaking the Body: Rehabilitation and Change. London: Routledge.

Stammer, N. (1999) 'Social Movements the Social Construction of Human Rights', Human Rights Quarterly Vol. 21(4): 980-1008.

Steadward, R. (1996) Integration and sport in the Paralympic movement. Sport Science Review, 5, 26-41.

Vanlandewijck, Y.C. \& Chappel, R. J. (1996) Integration and classification issues in competitive sports for athletes with disabilities. Sport Science Review, 5, 6588 .

Wolff, E.A., Torres, C., \& Hums, M.A. (2008). Olympism and the Olympic athlete with a disability. In O. Schantz, \& K. Gilbert, The Paralympics: Elite sport or freak show. Meyer \& Meyer. Pp. 167-175.

Zola, I. K. (1989) 'Towards the Necessary Universalizing of Disability Policy', The Milbank Memorial Fund Quarterly 67 (Supplement 2):401-28.

\footnotetext{
i Throughout this paper we used the term '[dis]abled athlete' because for us there is a double bind in the context of what is commonly refered to as disability sport. Convention with disability studies would adopted a person first approach. In other words the term for some should be 'athletes with a disability' To our mind this approach is ableist because society sees Paralympians largely as lacking ability we turn the idea on its head encouraging our readers exclude the [dis].

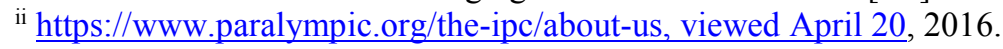

